\title{
A Study on Determining Weld Joint Hardening and a Quality Evaluation Algorithm for $9 \%$ Nickel Weld Joints Using the Dilution Ratio of the Base Material in Fiber Laser Welding
}

\author{
Minho Park ${ }^{1}$, Jisun Kim ${ }^{2}$, Changmin Pyo ${ }^{2}{ }^{(0)}$, Jaewoong Kim ${ }^{2, *}$ and Kwangsan Chun ${ }^{3, *}$ \\ 1 Southwestern Branch Institute, Research Institute of Medium \& Small Shipbuilding, Yeongam 58457, Korea; \\ mhpark@rims.re.kr \\ 2 Smart Manufacturing Process R\&D Group, Korea Institute of Industrial Technology, Gwangju 61012, Korea; \\ kimjisun@kitech.re.kr (J.K.); changmin@kitech.re.kr (C.P.) \\ 3 Industrial Application R\&D Group, Welding Engineering R\&D Department, Daewoo Shipbuilding \& Marine \\ Engineering Co., Ltd., Geoje-si 53302, Korea \\ * Correspondence: kjw0607@kitech.re.kr (J.K.); kschun@dsme.co.kr (K.C.); Tel.: +82-62-600-6480 (J.K.); \\ $+82-62-600-6302$ (K.C.)
}

\section{check for}

updates

Citation: Park, M.; Kim, J.; Pyo, C. Kim, J.; Chun, K. A Study on Determining Weld Joint Hardening and a Quality Evaluation Algorithm for $9 \%$ Nickel Weld Joints Using the Dilution Ratio of the Base Material in Fiber Laser Welding. Metals 2021, 11, 1308. https://doi.org/10.3390/ met11081308

Academic Editors: Aleksander Lisiecki and Pasquale Russo Spena

Received: 20 June 2021

Accepted: 16 August 2021

Published: 18 August 2021

Publisher's Note: MDPI stays neutral with regard to jurisdictional claims in published maps and institutional affiliations.

Copyright: (c) 2021 by the authors. Licensee MDPI, Basel, Switzerland. This article is an open access article distributed under the terms and conditions of the Creative Commons Attribution (CC BY) license (https:/ / creativecommons.org/licenses/by/ $4.0 /)$.

\begin{abstract}
The demand for LNG-powered ships and related equipment is rapidly increasing among major domestic and foreign carriers due to the strengthened IMO regulations on the sulfur content of ship fuel oil. LNG operation in a cryogenic environment requires a storage tank and fuel supply system that uses steel with excellent brittleness and fatigue strength. A ship using LNG is very sensitive to explosion and fire. For this reason, $9 \% \mathrm{Ni}$ is often used, because ships require high quality products with special materials and structural technologies that ensure operability at cryogenic temperatures. However, research to derive uniform welding quality is urgent because the deterioration of weld quality in the $9 \% \mathrm{Ni}$ steel welding process is caused by high process difficulty and differences in welding quality depending on a welder's skill set. This study proposes a method to guarantee a uniform quality of $9 \% \mathrm{Ni}$ steel in a fiber laser welding process by categorizing weld joint hardness according to the dilution ratio of a base material and establishing a standard for quantitative evaluation.
\end{abstract}

Keywords: ASTM A553-1 (9\% nickel steel); fiber laser welding; discriminant analysis; weld joint hardening; optimization

\section{Introduction}

The International Maritime Organization (IMO) has applied a high standard to the sulfur content of ship fuel oil since January 2020, and has finally confirmed a plan to reduce the sulfur content of ship fuel oil from its current level of $3.5 \%$ to $0.5 \%$ in 2020 . The IMO 2020 standards are legislated in each country around the world and the regulations are voluntarily applied to designated emission control areas with more stringent standards than other sea waters. Major domestic and foreign carriers are complying with the IMO's enhanced environmental regulations by considering the pros and cons of each alternative, such as installing a scrubber, using low-sulfur oil, or using LNG.

As eco-friendliness has become an international trend, a major energy transition is taking place around the world and the demand for liquefied natural gas (LNG) is increasing in the shipping sector as well. The bunkering industry, i.e., refueling LNG to LNG-powered ships, is also emerging worldwide. Equipment applied to an LNG propulsion ship can be broadly divided into the engine, fuel tank, fuel supply system, and fuel supply control system. A shipyard or a shipowner makes a packaged-type order, by which a tank or supply system can be directly installed onto a ship. However, a high-quality product with special materials and structural technologies for cryogenic operability is needed because 
operational disruption or anchoring due to equipment failure can cause serious economic damage [1-4].

An LNG storage tank is a cryogenic structure, and 9\% Ni steel, which has excellent mechanical properties and fatigue strength at room temperature and in low temperature environments, is widely used as a material for the inner tank of an LNG storage tank. Nine percent $\mathrm{Ni}$ steel has excellent impact toughness and fatigue strength in a cryogenic environment, and it is used worldwide in the production of LNG storage tanks because of its low material price compared to steel density. When using $9 \% \mathrm{Ni}$ steel, it is recommended that the absorption energy specified in domestic and foreign regulations should be $34 \mathrm{~J}$ or more at $196{ }^{\circ} \mathrm{C}$, but there are slight differences depending on the standard applied. Although it was first developed in 1944 by INCO (International Nickel Co., Ltd.) in the United States, today Japan is leading the improvement of 9\% Ni steel quality, developing welding technology and continuing research on safety as the trend moves towards largersized tanks [5,6].

The difficulty of the $9 \% \mathrm{Ni}$ welding process is high and the welding quality differs depending on a welder's skill set, because the welding wire has a lower melting point than the base material. Research is required to develop an advanced welding process technology and to derive uniform welding quality, because the more advanced countries that have already secured 9\% Ni steel welding technology are keeping such technology confidential. Therefore, it is urgent to pursue basic research to analyze the deterioration of welding quality that may occur in the $9 \%$ Ni steel welding process and to derive uniform high-quality weld joints by identifying their root causes.

This study has focused on the specific welding method and a material, namely FLW and $9 \%$ nickel steel. For analyzing the welding quality, the hardness of upper welding part after welding which is known to be vulnerable to cracks because of weld joint hardening was defined for evaluation. The concept of weld joint hardening was used as an output variable for the determination of a formula for evaluating the welding quality and many parameters related to the welding process were used as input variables. By optimizing those input variables based on the determined formula and a multi-objective optimization algorithm, the improved welding qualities were obtained.

This study was related to previous research which evaluated weldability with solidification crack susceptibility [7] and used similar evaluation methods such as welding test optimization. However, this study focused differently on weld joint hardening as an evaluation method.

Naturally, our previous studies are similar to other past research [7]. Yun [8] performed an optimization of fillet laser welding for $9 \% \mathrm{Ni}$ steel. $\mathrm{Na}$ [9] compared GTAW and FCAW for 9\% Ni steel. Kim [10] designed an LNG-fueled ship with 9\% Ni steel and evaluated welding performance. Watanabe [11] performed a double tension test of a surface notch of A553-1 steel. Liu et al. [12] performed a study to measure and analyze the fracture toughness of metals using machine learning models such as regression trees and neural networks.

In prior studies, the correlations between various variables and mechanical properties, as applied to the welding process of cryogenic steels such as the STS or Ni alloy series', were reviewed, and the process issues and quality deterioration that occurred when thet were used in LNG-related equipment were also reviewed. However, research on the quality of the weld joints of cryogenic steel did not reflect the complex alternating effects, and most of the studies were about implementing automation, high melting, or high speed to compensate for the shortcomings of manual welding $[13,14]$. In addition, research on the correlation between bead shape and weldability was conducted in previous studies to improve welding quality by establishing key factors affecting the bead formation, but similar size areas and heat-affected zones were derived intermittently even from different welding process variables, so the applicability of the analysis and consideration as limited to bead shape is reduced in an actual site. 
As such, an analysis with various perspectives is required to clearly distinguish the specific conditions that can produce a similar bead shape compared to the intermittent variables, and it is necessary to identify the phenomenon that causes the structure of a weld joint to be hardened by matching the characteristics generated from the correlation between the partially divided shapes within a weld joint to the dilution ratio of a weld joint.

In $9 \% \mathrm{Ni}$ steel, a higher dilution ratio of the base material results in lower strength. Therefore, excessive dilution of the base material should be avoided in order to secure the required strength. Although prior studies on the relationship between the dilution ratio and strength have found that the tensile strength does not change significantly even when there is a $10-20 \%$ change in the dilution ratio, it was reported that it may be lower than the API standard of $363 \mathrm{MPa}$ due to the hardening of a weld joint if it is $25 \%$ or more $[15,16]$.

Therefore, in this study, the dilution ratio formed in a weld joint was calculated for the fiber laser welding process applied to $9 \% \mathrm{Ni}$, a cryogenic steel, and the phenomenon in which a hardened weld joint is created compared to the heat-affected zone was identified in a procedure based on the calculated dilution ratio. Accordingly, this study tried to suggest a method of quantitatively evaluating the quality of a weld joint.

\section{Experimental Works}

The experiment was performed to determine the quality of a fiber laser weld joint of $9 \% \mathrm{Ni}$ steel and to develop the optimal process parameters. A MIYACHI ML-6950A model (Amada Weld Tech Co. Ltd., Chiba, Japan) $5 \mathrm{~kW}$ fiber laser welding machine was used, and a YASKAWA's DX100 model (Yaskawa Electric Co., Kitakyushu, Japan) MOTOMAN was used to configure the entire system, as shown in Figure 1.

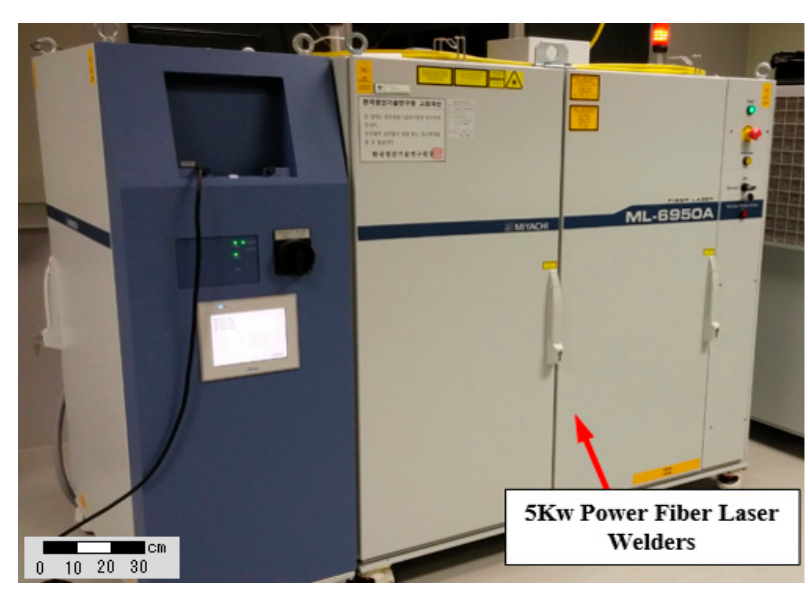

(a) The $5 \mathrm{kw}$ fiber laser power source.

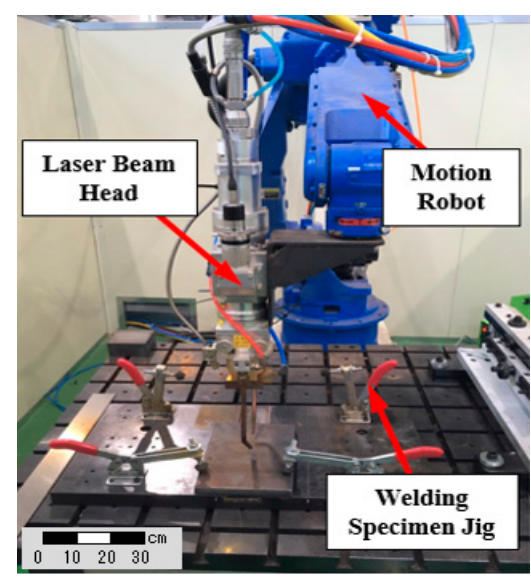

(b) Optical system and jig shape assembled in a six-axis robot.

Figure 1. Equipment for fiber laser welding.

The test piece used in the welding test was used in a size of $150 \mathrm{~mm}(\mathrm{~W}) \times 200 \mathrm{~mm}(\mathrm{H})$ $\times 15 \mathrm{~mm}(\mathrm{H})$ of $9 \% \mathrm{Ni}$ steel. The specimen was cleaned with ethyl alcohol and sandpaper to prevent foreign substances such as rust, scale, oxide, etc. from causing welding defects on the surface of a specimen to be welded. The schematic diagram of a fiber laser welding process is shown in Figure 2. The chemical composition and mechanical properties of $9 \%$ Ni steel are shown in Tables 1 and 2, respectively. 


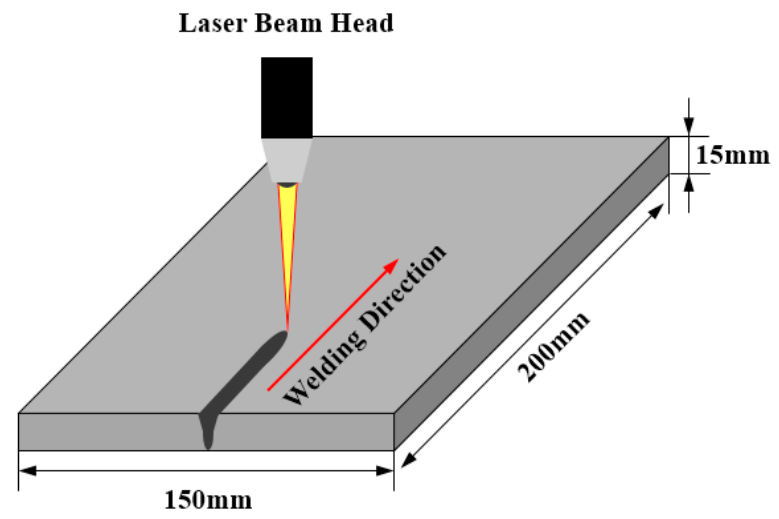

Figure 2. The fiber laser welding process.

Table 1. Chemical composition of base metal.

\begin{tabular}{cccccccc}
\hline Component & C & Si & Mn & S & P & Ni & Fe \\
\hline Percentage (wt. \%) & 0.05 & 0.67 & 0.004 & 0.003 & 0.25 & 9.02 & Bal. \\
\hline
\end{tabular}

Table 2. Mechanical properties of base metal.

\begin{tabular}{ccccc}
\hline Material & Yield Strength (MPa) & Tensile Strength (MPa) & Elongation (\%) & Hardness (HV) \\
\hline A553-1 & 651.6 & 701.1 & 26.6 & 243 \\
\hline
\end{tabular}

Laser power, defocusing, and welding speed were selected as input variables because the fiber laser welding process applied in this experiment welds by generating a keyhole while delivering the high energy required for welding to the material surface. Weldability was analyzed by collecting mechanical properties such as the heat-affected zone and weld joint hardness [11]. Figure 3 shows a schematic diagram for the measurement of the penetration shape of the weld joint [17].

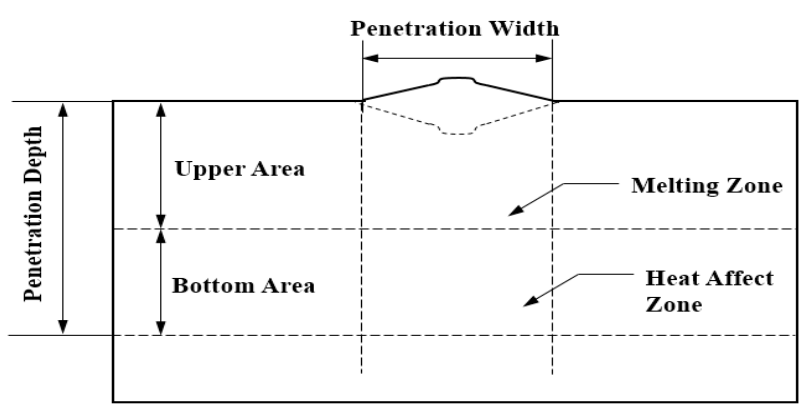

Figure 3. Schematic diagram of penetration geometry.

In this experiment, it is possible to estimate all the factor effects for the response of an output variable according to the change of an input variable, and the full factorial placement method (FFD) was applied to detect the correlation effect of higher orders. Full factorial design is a general $\mathrm{K}_{\mathrm{n}}$ factorial design DOE with $\mathrm{n}$ factors and $\mathrm{k}$ levels, and experiments are designed at the combination of all factor levels. Therefore, $K_{n}$ experiments should be performed even without repeated experiments. FFD forms a cube diagram of the experimental points in case of 3 factors and 2 levels, and the factor experiment by the factor arrangement method has the advantage that all factor effects can be estimated. The level and range of input variables (laser power, defocusing, welding speed) were chosen through preliminary experiments. A total of 18 experimental conditions were designed from $3^{2} \times 2$ ( 3 laser powers, 3 defocusing and 2 welding speeds). Tables 3 and 4 show the experimental variables, levels of the input variables, and the experimental conditions for a total of 18 trials, respectively. 
Table 3. Parameters and levels of fiber laser welding.

\begin{tabular}{ccccc}
\hline Parameter & Symbol & $\mathbf{- 1}$ & $\mathbf{0}$ & $\mathbf{1}$ \\
\hline Laser Power $(\mathrm{kW})$ & $L$ & 3.0 & 4.0 & 5.0 \\
Defocusing $(\mathrm{mm})$ & $D$ & -0.5 & 0.0 & 0.5 \\
Welding Speed (meter/minute, $\mathrm{m} / \mathrm{min})$ & $S$ & 0.5 & - & 0.8 \\
Fixed Parameter & \multicolumn{4}{c}{ Wavelength: $1070 \mathrm{~nm}$} \\
& Optical Fiber Diameter: $200 \mu \mathrm{m}$ \\
& Shielding Gas Flow Rate: Ar $18 \mathrm{~L} / \mathrm{min},(\mathrm{L} / \mathrm{min})$ \\
\hline
\end{tabular}

Table 4. Experimental conditions.

\begin{tabular}{cccccccc}
\hline Case No. & $\boldsymbol{L}$ & $\boldsymbol{D}$ & $\boldsymbol{S}$ & Case No. & $\boldsymbol{L}$ & $\boldsymbol{D}$ & $\boldsymbol{S}$ \\
\hline 1 & 3.0 & -0.5 & 0.5 & 10 & 3.0 & -0.5 & 0.8 \\
2 & 3.0 & 0.0 & 0.5 & 11 & 3.0 & 0.0 & 0.8 \\
3 & 3.0 & 0.5 & 0.5 & 12 & 3.0 & 0.5 & 0.8 \\
4 & 4.0 & -0.5 & 0.5 & 13 & 4.0 & -0.5 & 0.8 \\
5 & 4.0 & 0.0 & 0.5 & 14 & 4.0 & 0.0 & 0.8 \\
6 & 4.0 & 0.5 & 0.5 & 15 & 4.0 & 0.5 & 0.8 \\
7 & 5.0 & -0.5 & 0.5 & 16 & 5.0 & -0.5 & 0.8 \\
8 & 5.0 & 0.0 & 0.5 & 17 & 5.0 & 0.0 & 0.8 \\
9 & 5.0 & 0.5 & 0.5 & 18 & 5.0 & 0.5 & 0.8 \\
\hline
\end{tabular}

\section{Results}

\subsection{Penetration Geometry}

The BOP fiber laser welding of $9 \% \mathrm{Ni}$ steel, a cryogenic steel, was performed correctly according to the welding process parameters. Based on the result of the experiment, it was confirmed that good penetration was formed in general, and there were no pores or defects in appearance. To properly represent the cross-sectional appearance of a specimen, a $90 \%$ ethanol plus $10 \%$ nitric solution was mixed and used to etch the cross-section. An optical microscope system was used to measure the penetration shape accurately. Table 5 shows the welding cross-section and penetration measurement results taken with a $10 \times$ optical microscope.

Table 5. Results and Penetration Data.

\begin{tabular}{|c|c|c|c|c|c|c|c|c|c|}
\hline \multirow{2}{*}{ Test No. } & \multicolumn{4}{|c|}{ Penetration Width (mm) } & \multicolumn{4}{|c|}{ Penetration Depth (mm) } & \multirow{2}{*}{$\begin{array}{c}\text { Penetration } \\
\text { Geometry }\end{array}$} \\
\hline & 1 st & 2nd & 3 rd & Average & 1st & 2nd & 3 rd & Average & \\
\hline 1 & 3.93 & 3.90 & 3.90 & 3.91 & 6.49 & 6.47 & 6.51 & 6.49 & \\
\hline 2 & 3.19 & 3.18 & 3.17 & 3.18 & 6.64 & 6.66 & 6.64 & 6.65 & \\
\hline 3 & 4.73 & 4.72 & 4.69 & 4.71 & 7.21 & 7.22 & 7.15 & 7.19 & \\
\hline 4 & 5.82 & 5.86 & 5.84 & 5.84 & 8.52 & 8.51 & 8.55 & 8.53 & \\
\hline
\end{tabular}


Table 5. Cont.

\begin{tabular}{|c|c|c|c|c|c|c|c|c|c|}
\hline \multirow{2}{*}{ Test No. } & \multicolumn{4}{|c|}{ Penetration Width (mm) } & \multicolumn{4}{|c|}{ Penetration Depth (mm) } & \multirow{2}{*}{$\begin{array}{c}\text { Penetration } \\
\text { Geometry }\end{array}$} \\
\hline & 1st & 2nd & 3 rd & Average & 1st & 2nd & 3 rd & Average & \\
\hline 5 & 5.48 & 5.49 & 5.49 & 5.49 & 8.17 & 8.15 & 8.15 & 8.16 & \\
\hline 6 & 3.61 & 3.71 & 3.5 & 3.61 & 7.84 & 7.82 & 7.79 & 7.82 & \\
\hline 7 & 6.59 & 6.58 & 6.58 & 6.58 & 9.11 & 9.12 & 9.11 & 9.11 & \\
\hline 8 & 6.54 & 6.55 & 6.55 & 6.55 & 9.49 & 9.51 & 9.53 & 9.51 & \\
\hline 9 & 7.01 & 7.03 & 7.04 & 7.03 & 10.09 & 10.09 & 10.11 & 10.1 & \\
\hline 10 & 2.51 & 2.47 & 2.37 & 2.45 & 4.86 & 4.78 & 4.79 & 4.81 & \\
\hline 11 & 2.21 & 2.28 & 2.32 & 2.27 & 4.95 & 4.89 & 4.95 & 4.93 & \\
\hline 12 & 3.26 & 3.27 & 3.22 & 3.25 & 5.19 & 5.23 & 5.21 & 5.21 & \\
\hline 13 & 3.25 & 3.23 & 3.17 & 3.22 & 5.49 & 5.48 & 5.44 & 5.47 & \\
\hline 14 & 3.22 & 3.30 & 3.20 & 3.24 & 6.25 & 6.24 & 6.29 & 6.26 & \\
\hline 15 & 2.82 & 2.84 & 2.86 & 2.84 & 5.43 & 5.44 & 5.54 & 5.47 & \\
\hline 16 & 4.94 & 4.97 & 4.91 & 4.94 & 6.18 & 6.24 & 6.21 & 6.21 & \\
\hline 17 & 4.25 & 4.19 & 4.21 & 4.22 & 7.26 & 7.24 & 7.24 & 7.25 & \\
\hline 18 & 5.84 & 5.83 & 5.85 & 5.84 & 7.47 & 7.41 & 7.44 & 7.44 & \\
\hline
\end{tabular}




\subsection{Weld Joint Hardness}

A hardness test was performed to confirm the phenomenon of weld joint hardening caused by the change of internal strength and structure due to the difference in energy density of a laser keyhole when the fiber laser weld joint was solidified. For the hardness test, the Vickers hardness test was performed on the upper and lower parts and the heataffected zone, where the change in internal strength occurs. The load used in the hardness test was $0.5 \mathrm{~N}$ and analysis was performed at $0.83 \mathrm{~mm}$ intervals so as not to affect the nearby hardness. The 6-point positions for measuring the hardness of the HAZ were used as the left and right positions divided into thirds between each boundary of the penetration, the HAZ, and the base material. The $243 \mathrm{HV}$ value shown in Table 2 was used as the reference base material data to determine the hardness of the fiber laser welding. Figure 4 shows a schematic diagram of the hardness test for the weld joint of $9 \% \mathrm{Ni}$ steel. Table 6 shows the results of the hardness test of the upper and lower parts of a weld joint and the heat-affected zone. The hardness test result means the average value measured at 5 points. The hardness (lower part) of a fiber laser weld joint has a value between $339.4 \mathrm{HV}$ and $358.1 \mathrm{HV}$, which is higher than the $243 \mathrm{HV}$ hardness that is standard for $9 \% \mathrm{Ni}$ steel. Therefore, it is judged that sufficient weldability was obtained.

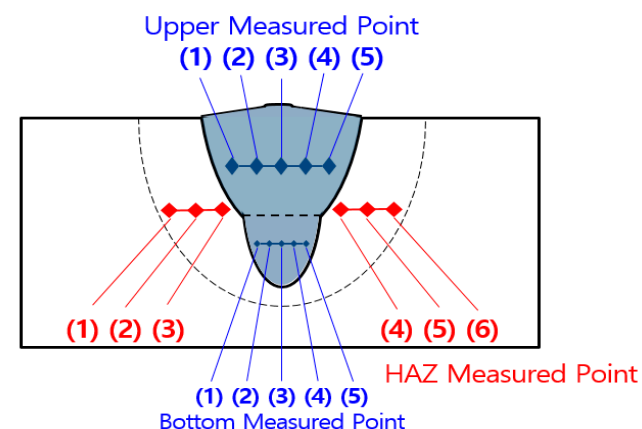

Figure 4. Schematic diagram of the hardness test.

Table 6. Results of hardness according to welding process and parameters.

\begin{tabular}{ccccccccccc}
\hline Test No. & & $\mathbf{1}$ & $\mathbf{2}$ & $\mathbf{3}$ & $\mathbf{4}$ & $\mathbf{5}$ & $\mathbf{6}$ & $\mathbf{7}$ & $\mathbf{8}$ & $\mathbf{9}$ \\
\hline & 1st & 266.6 & 296.4 & 283.3 & 277.4 & 314.6 & 270.7 & 314.6 & 308.3 & 283.7 \\
& 2nd & 262.1 & 300.0 & 279.0 & 279.8 & 305.9 & 277.1 & 312.7 & 301.1 & 287.5 \\
\multirow{5}{*}{ Upper (HV) } & 3rd & 264.9 & 294.6 & 282.6 & 276.1 & 299.2 & 274.2 & 306.0 & 303.3 & 287.1 \\
& 4th & 262.3 & 293.6 & 282.7 & 287.3 & 300.6 & 269.5 & 313.7 & 302.8 & 280.6 \\
& 5th & 264.8 & 291.1 & 280.9 & 284.7 & 311.4 & 269.0 & 314.7 & 302.8 & 284.6 \\
& Avg. & 264.2 & 295.2 & 281.7 & 281.1 & 306.3 & 272.1 & 312.4 & 303.7 & 284.7 \\
\hline & 1st & 343.9 & 345.7 & 346.3 & 358.0 & 351.5 & 349.8 & 355.3 & 346.6 & 350.4 \\
Bottom (HV) & 2nd & 344.9 & 345.6 & 344.9 & 358.3 & 350.6 & 349.5 & 356.2 & 348.1 & 350.0 \\
& 3rd & 345.0 & 346.5 & 346.4 & 358.1 & 349.5 & 350.5 & 356.4 & 347.4 & 350.4 \\
& 4th & 345.2 & 346.4 & 345.5 & 359.1 & 350.9 & 348.7 & 354.4 & 348.1 & 350.0 \\
& 5th & 345.3 & 345.9 & 346.2 & 356.7 & 350.6 & 349.7 & 355.2 & 346.5 & 350.6 \\
& Avg. & 344.9 & 346.0 & 345.8 & 358.1 & 350.6 & 349.6 & 355.5 & 347.4 & 350.3 \\
\hline \multirow{6}{*}{ HAZ (HV) } & 1st & 374.1 & 379.6 & 379.8 & 384.1 & 382.4 & 376.1 & 386.3 & 385.4 & 377.5 \\
& 2nd & 373.4 & 380.8 & 379.9 & 384.1 & 382.8 & 376.5 & 386.3 & 385.4 & 377.4 \\
& 3rd & 373.1 & 379.8 & 380.4 & 384.4 & 383.4 & 376.5 & 386.8 & 385.0 & 376.3 \\
& 4th & 373.2 & 380.0 & 381.0 & 384.0 & 382.8 & 376.3 & 386.0 & 385.6 & 378.5 \\
& 5th & 373.6 & 380.0 & 379.8 & 384.7 & 382.4 & 377.2 & 386.6 & 385.0 & 377.6 \\
& 6th & 373.7 & 379.6 & 380.6 & 384.3 & 382.7 & 376.8 & 385.9 & 385.8 & 378.5 \\
& Avg. & 373.5 & 380.0 & 380.3 & 384.3 & 382.7 & 376.6 & 386.3 & 385.4 & 377.7 \\
\hline
\end{tabular}


Table 6. Cont.

\begin{tabular}{|c|c|c|c|c|c|c|c|c|c|c|}
\hline \multicolumn{2}{|c|}{ Test No. } & 10 & 11 & 12 & 13 & 14 & 15 & 16 & 17 & 18 \\
\hline \multirow{6}{*}{ Upper (HV) } & $1 \mathrm{st}$ & 289.6 & 295.3 & 280.9 & 279.2 & 279.1 & 278.2 & 276.5 & 280.3 & 277.6 \\
\hline & 2nd & 284.2 & 295.6 & 278.1 & 276.2 & 276.1 & 279.8 & 275.7 & 280.4 & 280.9 \\
\hline & $3 \mathrm{rd}$ & 274.6 & 293.0 & 272.8 & 282.4 & 273.7 & 291.8 & 275.7 & 285.7 & 271.5 \\
\hline & 4 th & 284.3 & 289.3 & 276.3 & 277.4 & 272.8 & 282.1 & 274.1 & 279.6 & 274.9 \\
\hline & 5 th & 281.8 & 294.2 & 279.5 & 283.2 & 276.1 & 284.0 & 274.0 & 278.3 & 278.6 \\
\hline & Avg. & 282.9 & 293.5 & 277.5 & 279.7 & 275.5 & 283.2 & 275.2 & 280.9 & 276.7 \\
\hline \multirow{6}{*}{ Bottom (HV) } & 1st & 339.8 & 340.1 & 340.3 & 342.2 & 342.2 & 341.6 & 342.9 & 346.8 & 349.2 \\
\hline & 2nd & 340.0 & 339.3 & 339.7 & 343.1 & 342.7 & 341.1 & 343.3 & 347.5 & 348.5 \\
\hline & $3 \mathrm{rd}$ & 340.1 & 339.5 & 340.5 & 341.2 & 342.8 & 341.6 & 342.2 & 345.9 & 348.5 \\
\hline & 4th & 339.2 & 339.1 & 339.8 & 341.1 & 343.2 & 342.0 & 342.7 & 347.1 & 348.1 \\
\hline & 5th & 340.4 & 339.1 & 340.2 & 341.5 & 343.5 & 341.7 & 342.4 & 346.4 & 347.2 \\
\hline & Avg. & 339.9 & 339.4 & 340.1 & 341.8 & 342.9 & 341.6 & 342.7 & 346.7 & 348.3 \\
\hline \multirow{7}{*}{ HAZ (HV) } & $1 \mathrm{st}$ & 372.4 & 371.4 & 372.6 & 373.0 & 373.6 & 371.9 & 375.7 & 381.4 & 375.9 \\
\hline & 2nd & 371.9 & 371.8 & 371.8 & 373.2 & 373.4 & 372.8 & 375.5 & 381.2 & 376.3 \\
\hline & $3 \mathrm{rd}$ & 373.0 & 370.8 & 371.7 & 372.6 & 373.5 & 371.6 & 376.0 & 381.9 & 376.2 \\
\hline & 4th & 371.5 & 371.3 & 372.3 & 373.0 & 374.0 & 371.8 & 375.3 & 373.0 & 374.9 \\
\hline & 5th & 371.8 & 371.3 & 371.2 & 373.6 & 372.6 & 372.5 & 375.6 & 373.8 & 374.9 \\
\hline & 6th & 371.5 & 371.2 & 372.7 & 372.8 & 373.1 & 372.0 & 374.9 & 372.4 & 375.8 \\
\hline & Avg. & 372.0 & 371.3 & 372.1 & 373.1 & 373.4 & 372.1 & 375.5 & 377.3 & 375.7 \\
\hline
\end{tabular}

\subsection{Measurement of Weld Joint Dilution Ratio}

Since the shape of weld joint penetration in a fiber laser welding process differs according to beam shape and energy density due to the power and defocusing, there is a high possibility of hardening due to changes in the chemical composition and internal strength of the weld joint. In the fiber laser welding process, a special welding process in which a welding wire is not consumed, the dilution ratio can be defined as the area of the upper and lower parts divided by the keyhole and laser diameters. Figure 5 shows a schematic diagram of the method used to calculate the weld joint dilution ratio of a fiber laser welding process, and Figure 6 shows a picture of the calculation of a weld joint dilution ratio using the area analysis tool in a system using an optical microscope. Table 7 shows the dilution ratio of the weld joint area according to the fiber laser welding process parameters.

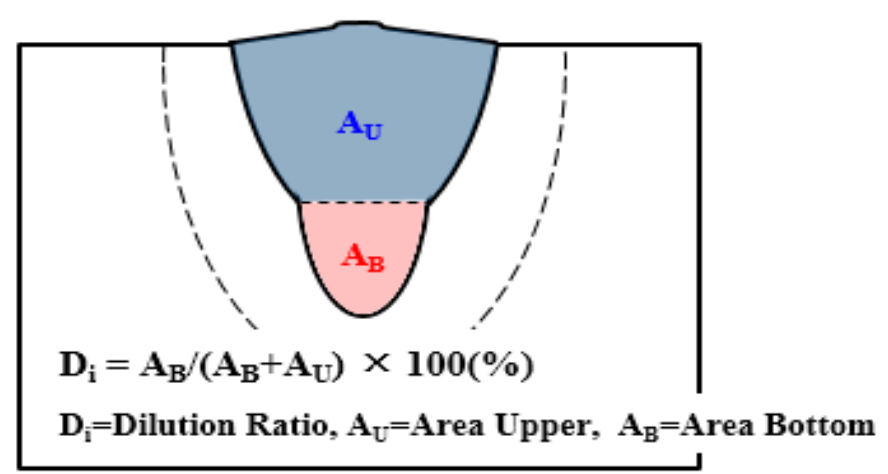

Figure 5. Schematic diagram of dilution ratio. 


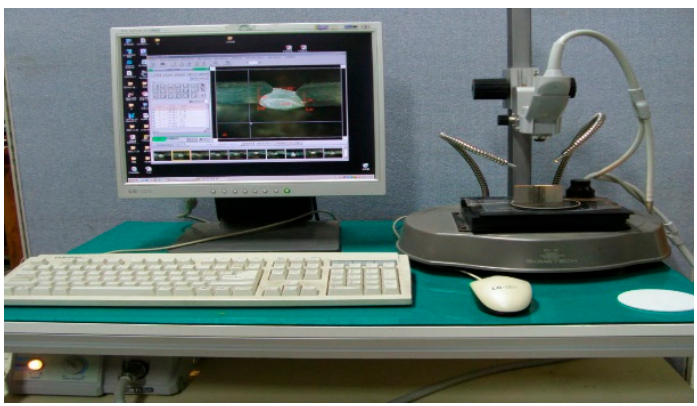

Figure 6. Optical microscope for dilution ratio measurement.

Table 7. Results of dilution ratio for fiber laser welding.

\begin{tabular}{|c|c|c|c|c|c|c|c|}
\hline $\begin{array}{l}\text { Test } \\
\text { No. }\end{array}$ & $\begin{array}{l}\text { Avg. Area Upper } \\
\left(\mathrm{mm}^{2}\right)\end{array}$ & $\begin{array}{l}\text { Avg. Area Bottom } \\
\left(\mathrm{mm}^{2}\right)\end{array}$ & $\begin{array}{c}\text { Dilution Ratio } \\
(\%)\end{array}$ & $\begin{array}{l}\text { Test } \\
\text { No. }\end{array}$ & $\begin{array}{l}\text { Avg. Area Upper } \\
\left(\mathrm{mm}^{2}\right)\end{array}$ & $\begin{array}{c}\text { Avg. Area Bottom } \\
\left(\mathrm{mm}^{2}\right)\end{array}$ & $\underset{(\%)}{\text { Dilution Ratio }}$ \\
\hline 1 & 6.38 & 1.45 & 18.53 & 10 & 3.00 & 0.62 & 17.20 \\
\hline 2 & 5.59 & 1.06 & 15.99 & 11 & 2.93 & 0.62 & 17.38 \\
\hline 3 & 8.85 & 1.81 & 16.97 & 12 & 4.37 & 0.91 & 17.16 \\
\hline 4 & 12.40 & 3.01 & 19.56 & 13 & 4.62 & 0.95 & 17.01 \\
\hline 5 & 11.49 & 2.40 & 17.30 & 14 & 5.12 & 1.14 & 18.14 \\
\hline 6 & 6.99 & 1.64 & 18.98 & 15 & 4.05 & 0.79 & 16.35 \\
\hline 7 & 15.63 & 3.09 & 16.52 & 16 & 7.67 & 1.75 & 18.61 \\
\hline 8 & 15.86 & 3.31 & 17.28 & 17 & 8.01 & 1.62 & 16.80 \\
\hline 9 & 18.19 & 3.93 & 17.77 & 18 & 11.17 & 2.46 & 18.05 \\
\hline
\end{tabular}

\section{Discriminant of Quality Characteristics of $\mathbf{9 \%}$ Ni Steel}

\subsection{Weld Joint Hardening according to Dilution Ratio}

In $9 \% \mathrm{Ni}$ steel, a higher dilution ratio of the base material causes a lower strength. Therefore, excessive dilution of a base material should be avoided to secure the required strength. Although the prior studies on the relationship between dilution ratio and strength have found that the tensile strength does not change significantly even when there is a $10-20 \%$ change in dilution ratio, it was reported that it may be lower than the API standard of $363 \mathrm{MPa}$ due to the hardening of the weld joint if the dilution ratio is $25 \%$ or more $[15,16]$. In addition, even under different welding conditions, the level of hardening of the heat-affected zones is similar when the amount of heat input is the same. However, the electromagnetic force and the energy density of the beam are different, so the effect on bead formation is different. This leads to the disadvantage of the increased hardness of a weld joint compared to the heat-affected zone. To address the shortcomings of prior studies that established the characteristics of a welding process limited to the bead shape as described above, the correlation between the concepts of dilution and the strength of the weld joint was established.

Since the shape of the weld penetration in the fiber laser welding process differs from the beam shape and energy density due to the laser power and defocusing, the possibility of hardening due to changes in the chemical composition and proof strength of the weld is very high. Therefore, although it is different from the method of calculating the area of the welded part analyzed in the general flux-cored arc welding process, the characteristics of the welded part that are changed by the welding current, arc voltage, welding wire, etc. are considered similarly to those of fiber laser welding. Therefore, in this study, the dilution rate was defined as the upper and lower division areas by the keyhole and the laser diameter by confirming that it is possible to analyze the strength reduction characteristics for the dilution rate even in fiber laser welding.

Therefore, in this section, the dilution ratio formed in a weld joint is calculated for each welding process and process variable and a standard for the generation of a weld joint hardness compared to the heat-affected zone is established. According to the calculated dilution ratio, to set up a stable weld joint dilution ratio standard. 
To analyze the correlation of hardness based on a dilution ratio that changes according to the penetration shape, a standard for hardening or scattering of the lower weld joint compared to the heat-affected zone was established. The difference and trend between the measured hardness of the heat-affected zone and the hardness of the lower weld joint were used to establish a standard dilution ratio that can avoid the hardening of a weld joint, as shown in Figure 7. As a result, the degree of hardness (difference between the hardness of the heat-affected zone and the hardness of the lower weld joint) of a fiber laser weld joint was found to be between $26.2 \mathrm{HV}$ and $38.0 \mathrm{HV}$, and the difference in hardness of a weld joint was confirmed to be $26.2 \mathrm{HV}$ or lower compared to the heat-affected zone when the dilution ratio of penetration was determined to be $17.7 \%$ or more. It was confirmed that the difference in hardness compared to the heat affected zone did not rise as the dilution ratio was increased. It is judged that this kind of hardening of a weld joint will make it difficult to secure quality against the brittle effect and durability.

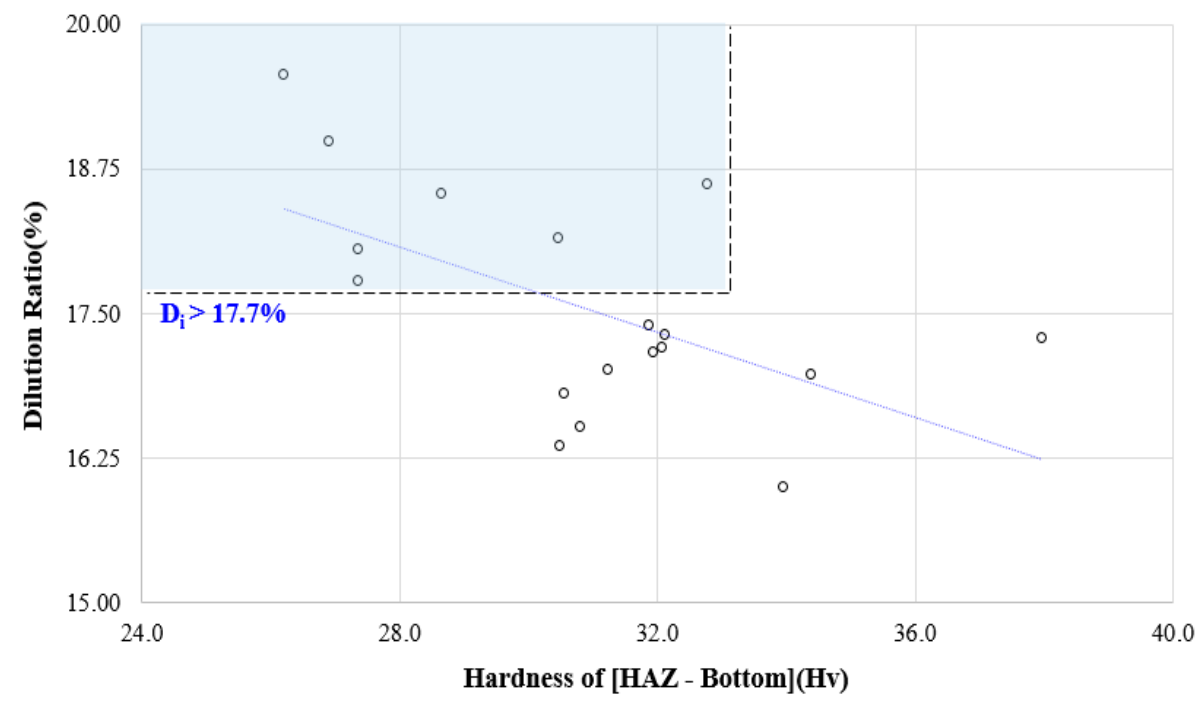

Figure 7. Weld joint hardening according to dilution ratio in fiber laser welding.

The standard $17.7 \%$ dilution ratio confirmed above is a standardized score, and can be used as an evaluation index for the process. When a high score is calculated, it means that a hardened structure of a weld joint was created. Therefore, the criteria for determining the hardening of a weld joint can be defined as shown in Table 8. These standardized scores can be later applied as learning data to determine the increase in weld joint hardness and brittleness according to the penetration shape and dilution ratio, in part to prevent the generation of a hardened structure and deterioration of weld joint strength due to energy density of a $9 \%$ Ni steel weld joint in which this welding process was applied.

Table 8. Weld joint hardening data for discriminant analysis in fiber laser welding.

\begin{tabular}{|c|c|c|c|c|c|c|c|}
\hline $\begin{array}{l}\text { Test } \\
\text { No. }\end{array}$ & $\begin{array}{c}\text { Hardness } \\
\text { Difference (HV) }\end{array}$ & $\begin{array}{c}\text { Dilution Ratio } \\
(\%)\end{array}$ & $\begin{array}{l}\text { Weld Joint } \\
\text { Hardening }\end{array}$ & $\begin{array}{l}\text { Test } \\
\text { No. }\end{array}$ & $\begin{array}{c}\text { Hardness } \\
\text { Difference (HV) }\end{array}$ & $\begin{array}{c}\text { Dilution Ratio } \\
(\%)\end{array}$ & $\begin{array}{l}\text { Weld Joint } \\
\text { Hardening }\end{array}$ \\
\hline 1 & 28.7 & 18.53 & Regard & 10 & 32.1 & 17.20 & Regardless \\
\hline 2 & 34.0 & 15.99 & Regardless & 11 & 31.9 & 17.38 & Regardless \\
\hline 3 & 34.4 & 16.97 & Regardless & 12 & 32.0 & 17.16 & Regardless \\
\hline 4 & 26.2 & 19.56 & Regard & 13 & 31.3 & 17.01 & Regardless \\
\hline 5 & 32.1 & 17.30 & Regardless & 14 & 30.5 & 18.14 & Regard \\
\hline 6 & 26.9 & 18.98 & Regard & 15 & 30.5 & 16.35 & Regardless \\
\hline 7 & 30.8 & 16.52 & Regardless & 16 & 32.8 & 18.61 & Regard \\
\hline 8 & 38.0 & 17.28 & Regardless & 17 & 30.6 & 16.80 & Regardless \\
\hline 9 & 27.4 & 17.77 & Regard & 18 & 27.4 & 18.05 & Regard \\
\hline
\end{tabular}




\subsection{Discriminant Analysis}

The system to determine the weld joint hardening in the fiber laser welding process of $9 \% \mathrm{Ni}$ steel is a technique used to determine the affiliation of the input data by making a model using the collected data and entering it into developed group learning data [18-20].

For the weld joint hardening system developed in this study, a discriminant model was developed using the SVM (support vector machine) technique. Unlike neural networks, SVM is not a principle of minimizing the existing empirical risk, but an approximate implementation that minimizes the structural risk. It is difficult to generalize and it is easy to overfit the model to minimize the empirical risk used in the existing artificial neural network. On the other hand, SVM minimizes the upper limit of the expected risk by minimizing the structural risk, unlike minimizing the empirical risk that minimizes the error on the training data. In other words, the method of minimizing structural risk is based on a test error term whose range is determined by the sum of learning error ratios and a term dependent on the VC-dimension of the learning machine. By minimizing the sum of these two terms, it is possible to obtain better classification performance than the conventional pattern discriminant. In the problem of finding the hyperplane that maximizes margin in the two classes, where linear discrimination is possible based on the VC (Vapnik-Chervonenkis) theory and Equation (1), this study tried to determine the possibility of hardening of a weld joint in process [21].

$$
w \cdot x+b=0
$$

where $w$ is the weight vector, $x$ is the input vector, and $b$ is the reference value, and the SVM technique described above sequentially performs minimization of complex calculations in the QP (quadratic programming) process. The variables for learning in the weld joint hardening discrimination model are welding process variables (laser power, defocusing, welding speed), penetration shape (penetration width, penetration depth), upper and bottom hardness, heat affected zone hardness (HAZ hardness) and the dilution ratio. One hundred and eighty data points were entered with 10 multiple variables. For the groups to determine the hardening of a weld joint, the Regard Group was defined as 1 and the Regardless Group was defined as 0, to confirm the discrimination performance predicted by the SVM technique.

Table 9 shows the learning data to discriminate the hardening of a weld joint and Table 10 and Figure 8 quantitatively show the group discrimination performance predicted by the data learned through the SVM technique.

Table 9. Learning data for discriminants of fiber laser welding quality.

\begin{tabular}{|c|c|c|c|c|c|c|c|c|c|c|}
\hline Test No. & $L$ & $D$ & $S$ & $P_{W}$ & $P_{\mathrm{D}}$ & $H_{U}$ & $H_{\mathrm{B}}$ & $H_{H}$ & $D_{\mathrm{i}}$ & Group \\
\hline 1 & 3.0 & -0.5 & 0.5 & 3.91 & 6.49 & 264.2 & 344.9 & 373.5 & 18.53 & Regard \\
\hline 2 & 3.0 & 0.0 & 0.5 & 3.18 & 6.65 & 295.2 & 346.0 & 380.0 & 15.99 & Regardless \\
\hline 3 & 3.0 & 0.5 & 0.5 & 4.71 & 7.19 & 281.7 & 345.8 & 380.3 & 16.97 & Regardless \\
\hline 4 & 4.0 & -0.5 & 0.5 & 5.84 & 8.53 & 281.1 & 358.1 & 384.3 & 19.56 & Regard \\
\hline 5 & 4.0 & 0.0 & 0.5 & 5.49 & 8.16 & 306.3 & 350.6 & 382.7 & 17.30 & Regardless \\
\hline 6 & 4.0 & 0.5 & 0.5 & 3.61 & 7.82 & 272.1 & 349.6 & 376.6 & 18.98 & Regard \\
\hline 7 & 5.0 & -0.5 & 0.5 & 6.58 & 9.11 & 312.4 & 355.5 & 386.3 & 16.52 & Regardless \\
\hline 8 & 5.0 & 0.0 & 0.5 & 6.55 & 9.51 & 303.7 & 347.4 & 385.4 & 17.28 & Regardless \\
\hline 9 & 5.0 & 0.5 & 0.5 & 7.03 & 10.1 & 284.7 & 350.3 & 377.7 & 17.77 & Regard \\
\hline 10 & 3.0 & -0.5 & 0.8 & 2.45 & 4.81 & 282.9 & 339.9 & 372.0 & 17.20 & Regardless \\
\hline 11 & 3.0 & 0.0 & 0.8 & 2.27 & 4.93 & 293.5 & 339.4 & 371.3 & 17.38 & Regardless \\
\hline 12 & 3.0 & 0.5 & 0.8 & 3.25 & 5.21 & 277.5 & 340.1 & 372.1 & 17.16 & Regardless \\
\hline 13 & 4.0 & -0.5 & 0.8 & 3.22 & 5.47 & 279.7 & 341.8 & 373.1 & 17.01 & Regardless \\
\hline 14 & 4.0 & 0.0 & 0.8 & 3.24 & 6.26 & 275.5 & 342.9 & 373.4 & 18.14 & Regard \\
\hline 15 & 4.0 & 0.5 & 0.8 & 2.84 & 5.47 & 283.2 & 341.6 & 372.1 & 16.35 & Regardless \\
\hline 16 & 5.0 & -0.5 & 0.8 & 4.94 & 6.21 & 275.2 & 342.7 & 375.5 & 18.61 & Regard \\
\hline 17 & 5.0 & 0.0 & 0.8 & 4.22 & 7.25 & 280.9 & 346.7 & 377.3 & 16.80 & Regardless \\
\hline 18 & 5.0 & 0.5 & 0.8 & 5.84 & 7.44 & 276.7 & 348.3 & 375.7 & 18.05 & Regard \\
\hline
\end{tabular}

$L$ : laser power $(\mathrm{kW}) ; D$ : defocusing $(\mathrm{mm}) ; S$ : welding speed $(\mathrm{m} / \mathrm{min}) ; P_{\mathrm{W}}$ : penetration width $(\mathrm{mm}) ; P_{\mathrm{D}}$ : penetration depth $(\mathrm{mm}) ; H_{\mathrm{U}}: \mathrm{upper}$ hardness $(\mathrm{HV}) ; H_{\mathrm{B}}$ : bottom hardness $(\mathrm{HV}) ; H_{\mathrm{H}}$ : HAZ hardness $(\mathrm{HV}) ; D_{\mathrm{i}}$ : dilution ratio $(\%)$. 
Table 10. Results of group discriminants for weld joint hardening according to SVM.

\begin{tabular}{cccccc}
\hline Test No. & Measured Group & Predicted Group & Test No. & Measured Group & Predicted Group \\
\hline 1 & 1 & $1(1.00)$ & 10 & 0 & 0 \\
2 & 0 & $0(0.00)$ & 11 & 0 & $0.00)$ \\
3 & 0 & $0(0.01)$ & 12 & 0 & $0.00)$ \\
4 & 1 & $1(1.00)$ & 13 & 1 & $0(0.01)$ \\
5 & 0 & $0(0.00)$ & 15 & 0 & $1(0.95)$ \\
6 & 1 & $1(1.00)$ & 16 & 1 & $0(0.00)$ \\
7 & 0 & $0(0.00)$ & 17 & 0 & $1(1.00)$ \\
9 & 0 & $0(0.00)$ & 18 & 1 & $0(0.01)$ \\
\hline
\end{tabular}

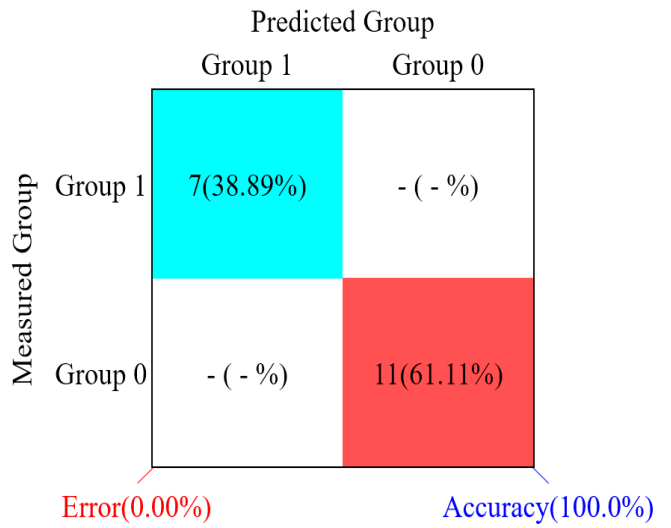

(a) Performance evaluation for SVM

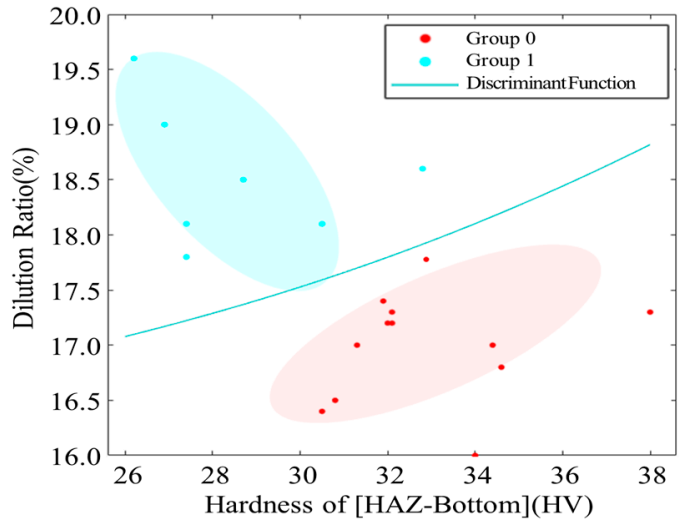

(b) Discriminant graph for SVM

Figure 8. Weld joint hardening discriminant in fiber laser welding: (a) Performance evaluation for SVM and (b) Discriminant graph for SVM.

\section{Optimization of Fiber Laser Welding of $\mathbf{9 \%}$ Ni Steel}

\subsection{Development of Mathematical Model Welding Factors}

The response surface analysis method was used for analysis, as in the previous research [7]. The functional relationship between the input variables $x_{1}, x_{2}, x_{3}, \cdots x_{k}$ and the output variable $y$ is expressed by Equation (2). Considering the predictive ability of linear and nonlinear models, Equation (3) is expressed as a second order regression model if it is assumed the predicted value of the output variable, i.e., the welding factor, has a linear relationship with an input variable.

$$
\begin{gathered}
Y_{i}=f\left(x_{1}, x_{2}, x_{3}\right), \\
Y_{i}=\beta_{0}+\sum_{i=1}^{k} \beta_{i} x_{i}+\sum_{i \leq j}^{k} \beta_{i j} x_{i} x_{j}+\epsilon .
\end{gathered}
$$

Equation (3) can be arranged as Equation (4) by the least squares method:

$$
\hat{Y}_{i}=\hat{\beta}_{i}+\sum_{i=1}^{k} \hat{\beta}_{i} x_{i}+\sum_{i \leq j}^{k} \hat{\beta_{i j}} x_{i} x_{j}+c
$$

In this study, Equation (4) can be expanded as Equation (5) since the number of input variables is 3 ; that is, $k=3$.

$$
\hat{Y_{i}}=\hat{\beta_{0}}+\hat{\beta_{1}} x_{1}+\hat{\beta_{2}} x_{2}+\hat{\beta_{3}} x_{3}+\hat{\beta_{11}} x_{1}^{2}+\hat{\beta_{22}} x_{2}^{2}+\hat{\beta_{33}} x_{3}^{2}+\hat{\beta_{12}} x_{1} x_{2}+\hat{\beta_{13}} x_{1} x_{3}+\hat{\beta_{23}} x_{2} x_{3},
$$


where, $\hat{Y}_{i}$ is the estimator of welding characteristics, $x_{i}$ is the code unit of the input variables (welding process variables and mechanical properties), $\hat{\beta_{0}}, \hat{\beta_{i}}, \hat{\beta_{i j}}$ are the min. square estimators of $\beta_{0}, \beta_{i}, \beta_{i j}$, respectively, and $\epsilon$ represents an error. To develop Equation (5) from the above regression model, it is necessary to obtain relevant data through many experiments.

To obtain relevant data through experiments, numerous trials and errors and economic losses may occur. To reduce such losses, a full factorial design was applied among the response surface analysis methods of the DOE method that well reflects the second order regression model, and the coefficients of each term were calculated using MINITAB.

The mathematical prediction models of penetration width, penetration depth, upper and bottom hardness, HAZ hardness and the dilution ratio developed using regression coefficients and Equation (5), can be expressed using Equations (6)-(11):

$$
\begin{gathered}
P_{\mathrm{W}}=8.871-2.537 L-1.354 D-2.463 S+0.5375 L^{2}+1.440 D^{2}-0.06251 L D-0.7389 L S+2.556 D S \\
P_{\mathrm{D}}=5.651+1.089 L-1.154 D-2.174 S+0.1233 L^{2}-0.5567 D^{2}+0.2800 L D-1.356 L S+0.7222 D S \\
H_{\mathrm{U}}=-660.3+761.7 S-190.7 P_{\mathrm{W}}+314.2 P_{\mathrm{D}}-7.524 P_{\mathrm{W}}^{2}-23.84 P_{\mathrm{D}}^{2}+78.21 S P_{\mathrm{W}}-158.6 S P_{\mathrm{D}}+29.12 P_{\mathrm{W}} P_{\mathrm{D}} \\
H_{\mathrm{B}}=123.1+144.7 S-24.54 P_{\mathrm{W}}+63.30 P_{\mathrm{D}}-0.4559 P_{\mathrm{W}}^{2}-4.080 P_{\mathrm{D}}^{2}+9.244 S P_{\mathrm{W}}-27.10 S P_{\mathrm{D}}+3.248 P_{\mathrm{W}} P_{\mathrm{D}} \\
H_{\mathrm{H}}=97.64+202.1 S-38.62 P_{\mathrm{W}}+83.79 P_{\mathrm{D}}-2.850 P_{\mathrm{W}}^{2}-6.157 P_{\mathrm{D}}^{2}+19.67 S P_{\mathrm{W}}-42.32 S P_{\mathrm{D}}+7.325 P_{\mathrm{W}} P_{\mathrm{D}} \\
D_{\mathrm{i}}=2690.2+35.34 P_{\mathrm{W}}-16.43 H_{\mathrm{B}}+0.7608 H_{\mathrm{U}}+0.1383 P_{\mathrm{W}}^{2}+0.02731 H_{\mathrm{B}}^{2} \\
+0.00301 H_{\mathrm{U}}^{2}-0.1029 P_{\mathrm{W}} H_{\mathrm{B}}-0.0023 P_{\mathrm{W}} H_{\mathrm{U}}-0.0073 H_{\mathrm{B}} H_{\mathrm{U}}
\end{gathered}
$$

To check the predictive ability of the developed mathematical prediction model, the graph showing the error range by comparing the average values of the measured welding factors for each experimental condition with the predicted welding factors, is shown in Figure 9. As shown in Table 11, the prediction model error range showed reliable results in general.

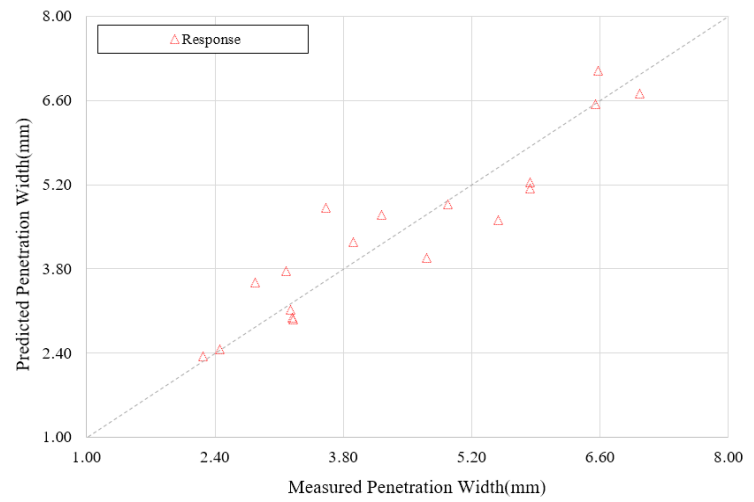

(a) Penetration width

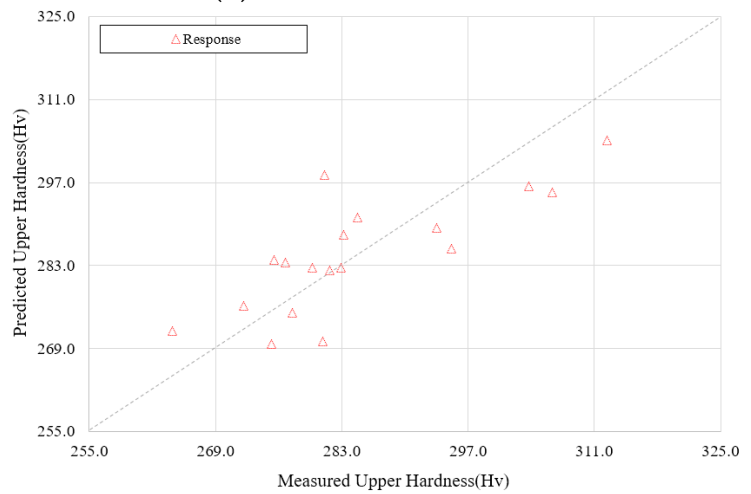

(c) Upper hardness

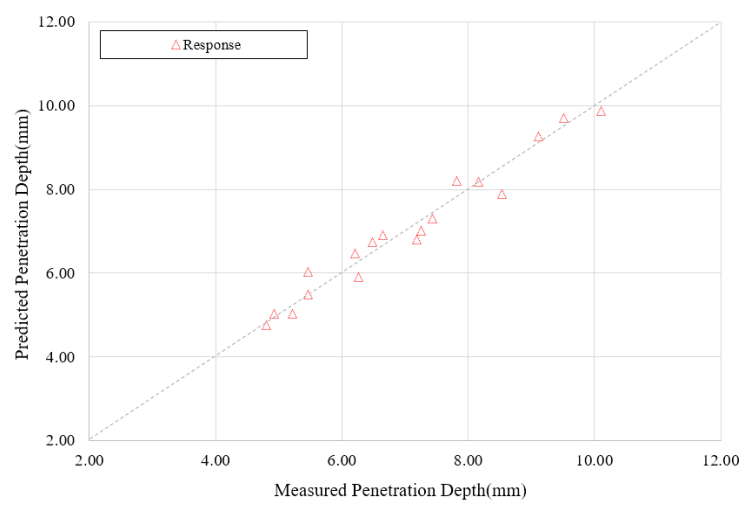

(b) Penetration depth

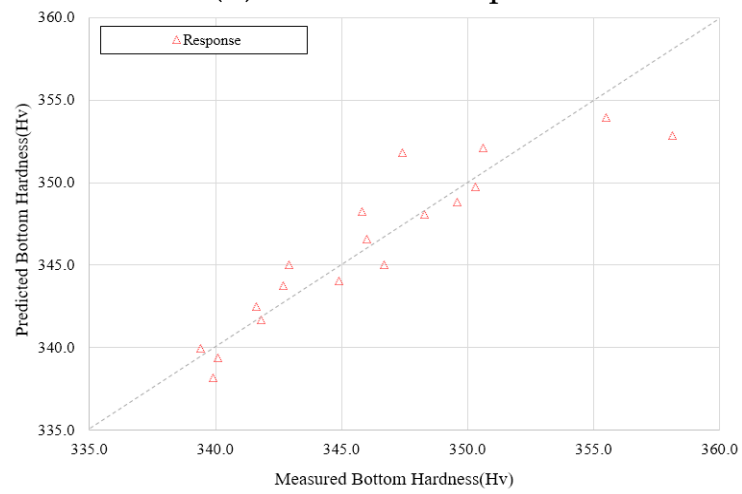

(d) Bottom hardness

Figure 9. Cont. 


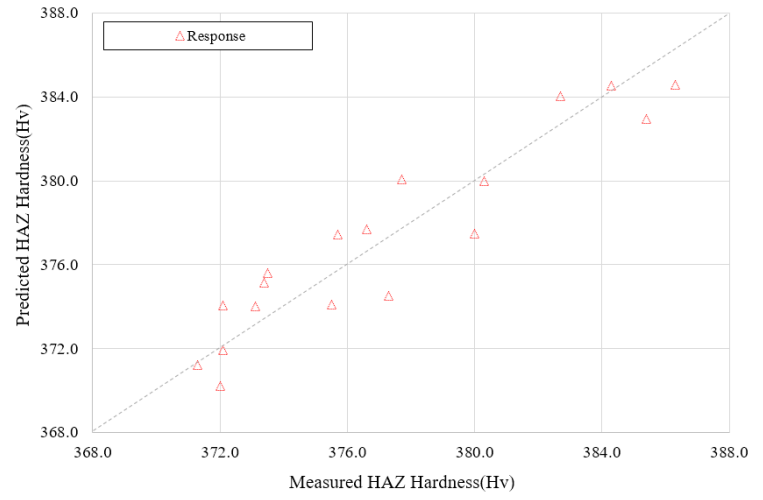

(e) HAZ hardness

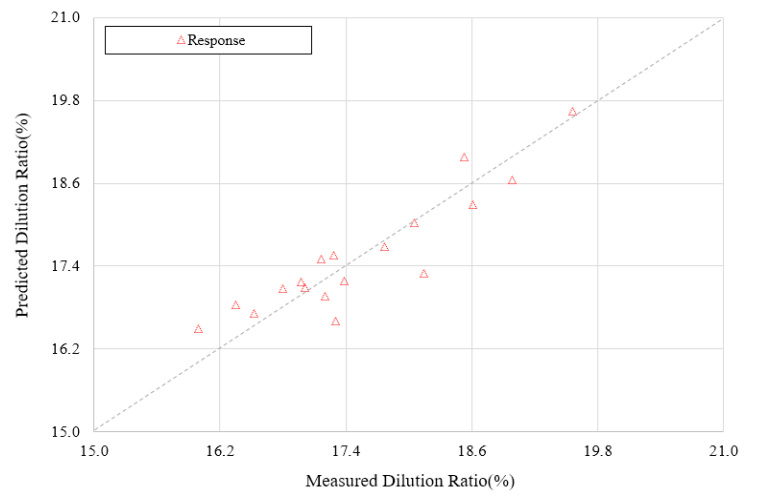

(f) Dilution ratio

Figure 9. Comparison between measured and predicted welding factors according to the mathematical model: (a) penetration width, (b) penetration depth, (c) upper hardness, (d) bottom hardness, (e) HAZ hardness and (f) dilution ratio.

Table 11. Analysis variance tests for predicted model for welding factors.

\begin{tabular}{ccc}
\hline Design Parameter & SE (Standard Error) & $\mathbf{R}^{\mathbf{2}}$ (Coefficient of Determination, \%) \\
\hline$P_{\mathrm{W}}$ & 0.769 & 86.4 \\
$P_{\mathrm{D}}$ & 0.423 & 96.3 \\
$H_{\mathrm{U}}$ & 10.83 & 71.1 \\
$H_{\mathrm{B}}$ & 2.847 & 84.4 \\
$H_{\mathrm{H}}$ & 2.541 & 80.7 \\
$D_{\mathrm{i}}$ & 0.568 & 83.2 \\
\hline
\end{tabular}

In addition, the ANOVA (analysis of variable) results of the predictive model confirmed a high coefficient of determination of $96.3 \%$ at the maximum penetration depth and a minimum coefficient of determination of $71.1 \%$ at the upper hardness of the weld joint. This means that it is possible to make predictions using the coefficient of determination for the entire variation of welding factors and the interaction, when the independent influence of input variables affecting the regression model are simultaneously considered.

\subsection{Optimization for the Welding Process of 9\% Ni Steel}

The MOO (multi-objective optimization) algorithm that was used in this study is a technique used to search for non-dominant solutions by mimicking the evolutionary process of an organism in an optimization problem with multiple objectives. This algorithm was used as in the previous research [7].

First of all, based on the mathematical definition of Pareto Domination as in Equation (12), the Pareto optimal set $P_{0}$, and a set of non-dominant solutions $x_{i}$, were created in a destination space. Genes belonging to the Pareto optimal set $P_{0}$-that is, decision vectorsare randomly generated in as large a quantity as the number of populations in the decision space. A cluster with a high degree of non-dominance and the best fit is generated to calculate the crowding distance and an optimal solution set with a high cluster distance is judged to have more variety of solutions, at which point a multi-purpose optimal solution is derived [22-24]:

$$
\forall i \in\{1,2,3, \cdots, n\}: f_{i}(a) \leq f_{i}(b) \wedge \exists j \in\{1,2,3, \cdots, n\}: f_{i}(a) \leq f_{i}(b) .
$$

In general, the multipurpose optimization problem can be described as a vector function $f(x)$ that maps $\mathrm{m}$ parameters to $\mathrm{n}$ objectives. Here, $x$ is a decision vector, $X$ is a parameter space, $y$ is an objective vector, and $Y$ is an objective space. Decision vector a is said to dominate decision vector $b$. Also, it is written as $a<b$ ( $a$ dominates $b$ ). Also, for an arbitrary decision vector $a$, if no vector in the subset $X$ of the decision vectors dominates $a$, it is said that the decision vector $a$ is non-dominated by $X$. Based on the above theorem, 
the program schematic diagram of the MOO optimization method is shown in Figure 10 and MATLAB, a commercial numerical analysis program, was used to apply and modify the optimization method. To optimize the welding process variables when the hardening of a weld joint has occurred, the same 180 data in Table 9 and the variables and levels to drive the MOO optimization technique are shown in Table 12.

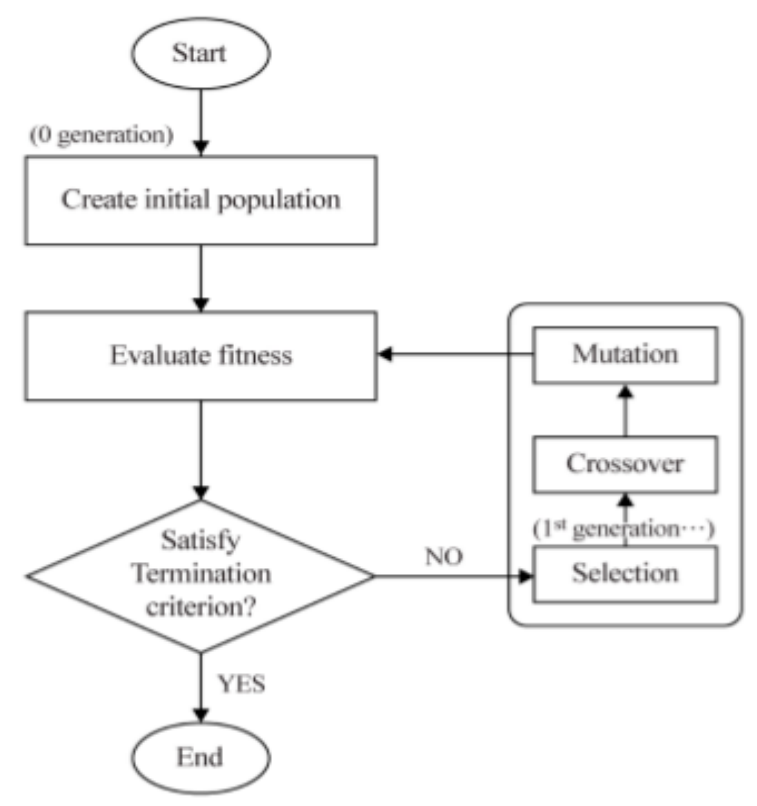

Figure 10. Flow chart of the multi-objective optimization (MOO) method to predict the welding parameters.

Table 12. MOO algorithm parameters and their values.

\begin{tabular}{|c|c|c|}
\hline \multicolumn{2}{|c|}{ Optimal Method } & $\begin{array}{l}\text { MOO (Multi-Objective } \\
\text { Optimization) }\end{array}$ \\
\hline \multirow{3}{*}{ Range of Local Parameters } & $L$ (Laser Power) & {$[-0.5 \leq$ Input $\leq+0.5] \mathrm{kW}$} \\
\hline & $D$ (Defocusing) & {$[-0.25 \leq$ Input $\leq+0.25] \mathrm{mm}$} \\
\hline & $S$ (Welding Speed) & {$[-0.15 \leq$ Input $\leq+0.15] \mathrm{m} / \mathrm{min}$} \\
\hline \multirow{2}{*}{$\begin{array}{l}\text { Range of Constraints } \\
\text { Fitness Factor }\end{array}$} & $D_{\mathrm{i}}$ (Dilution Ratio) & $D_{\mathrm{i}} \leq \overline{17} .7 \%$ \\
\hline & Population Size & $50,60,70,80,90,100$ \\
\hline \multicolumn{2}{|c|}{ Solver } & Constrained nonlinear minimization \\
\hline \multicolumn{2}{|c|}{ Algorithm } & Trust region reflective algorithm \\
\hline \multicolumn{2}{|c|}{ Derivatives } & Gradient supplied \\
\hline
\end{tabular}

In the MOO technique, a range of fiber laser welding process parameters was chosen from the minimum [ $3 \mathrm{~kW},-0.5 \mathrm{~mm}, 0.5 \mathrm{~m} / \mathrm{min}]$ to the maximum [ $5 \mathrm{~kW},+0.5 \mathrm{~mm}$, $0.8 \mathrm{~m} / \mathrm{min}]$. The purpose of this study was to analyze a multi-purpose optimization problem that considers weld joint hardness as a criterion to evaluate the quality deterioration characteristics of a weld joint in 9\% Ni steel. Therefore, Equations (13)-(15) represent the objective function $f(x)$ of an arbitrary system having $x$ as a variable and the constraints and ranges required to optimize this function [25].

$$
\begin{gathered}
\text { Optimize } f(L, D, S) \\
g(L, D, S) \\
D_{\mathrm{i}}<17.7
\end{gathered}
$$


Test numbers 4 and 14 were selected to follow the MOO algorithm and Table 13 shows the welding process variables, expected welding factors, and discrimination results that were modified to satisfy the constraints according to the optimization procedure.

Table 13. Results of welding parameters modified by optimization process.

\begin{tabular}{|c|c|c|c|c|c|c|c|c|c|c|c|c|c|}
\hline \multirow{2}{*}{ Test No. } & \multicolumn{3}{|c|}{ Original } & \multicolumn{3}{|c|}{ Modified } & \multicolumn{6}{|c|}{ Welding Factors } & \multirow{2}{*}{ Group } \\
\hline & $L$ & $D$ & $S$ & $L$ & $D$ & $S$ & $P_{\mathrm{W}}$ & $P_{\mathrm{D}}$ & $H_{\mathrm{U}}$ & $H_{\mathrm{B}}$ & $H_{H}$ & $D_{\mathrm{i}}$ & \\
\hline 4 & 4.0 & -5.0 & 0.5 & 3.91 & -0.51 & 0.51 & 5.0 & 7.7 & 289.9 & 350.4 & 382.4 & 16.7 & Regardless \\
\hline 14 & 4.0 & 0.0 & 0.8 & 3.84 & -0.08 & 0.86 & 2.5 & 5.3 & 298.0 & 343.5 & 376.0 & 16.6 & Regardless \\
\hline
\end{tabular}

The possibility of hardening of a weld joint and the effectiveness of optimizing the welding process for $9 \% \mathrm{Ni}$ steel was confirmed by performing a comparative analysis with the hardening of a weld joint caused by the existing input variables, as seen in Figure 11. The $X$-axis represents the difference in hardness values between the HAZ and the bottom, and the $\mathrm{Y}$-axis represents the dilution ratio. This graph was constructed to compare and examine whether the hardness of the bottom was close ( $\triangle \mathrm{HV}=\mathrm{HV} H A Z-\mathrm{HV}$ bottom) to the hardness of the HAZ with the dilution ratio. Finally, it was confirmed that the two raw data points selected in the fiber laser welding process, satisfied the dilution ratio of $17.7 \%$ or less, which is the limiting condition for the hardening of a weld joint, and the quality degradation characteristics appearing in the previous process variables were resolved by the modified process variables.

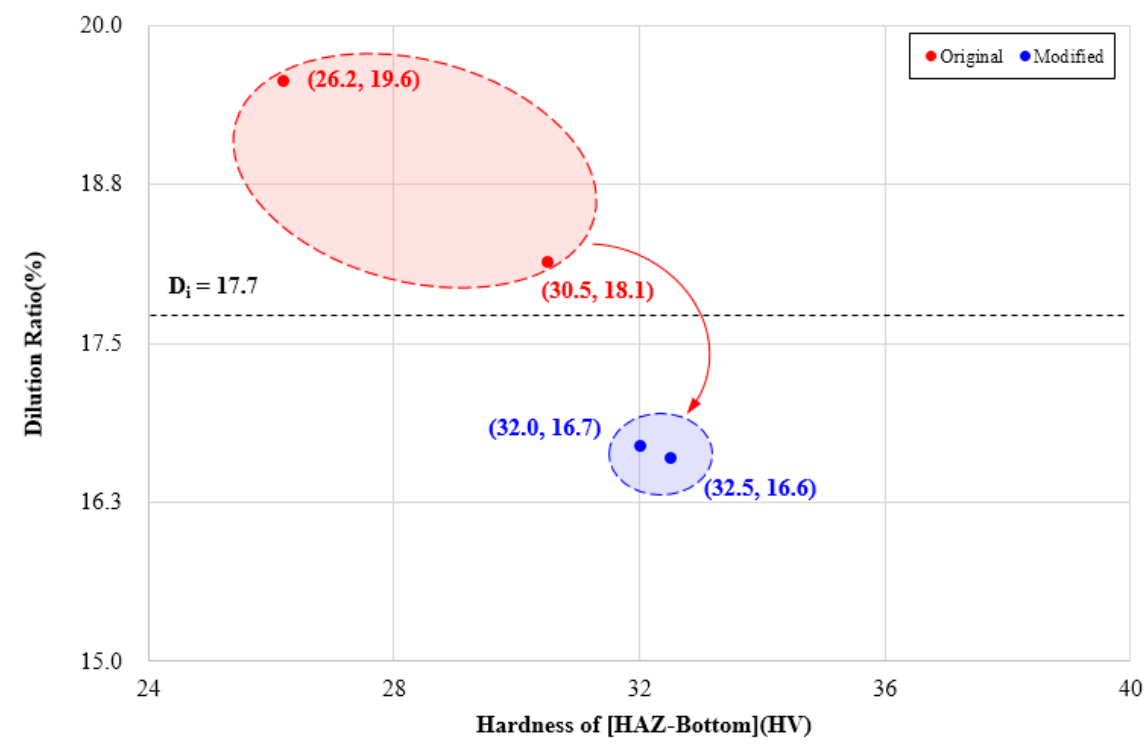

Figure 11. Weld joint hardening distributions using modified input parameters.

\section{Conclusions}

This study tried to optimize the welding process for $9 \% \mathrm{Ni}$ steel, which is predominantly used in the LNG storage tank industry. After establishing the criteria for the hardening of a weld joint in the process, conducting learning in the discriminant function, and optimizing the process variables for hardening of a weld joint using the discriminant group, these conclusions were obtained:

(1) The appropriate weldability of a weld joint was confirmed by measuring the penetration shape, mechanical strength, penetration area, etc. of a weld joint derived from the fiber laser welding test. It was found that the hardening of a weld joint depends on the energy density applied to the weld joint and the ratio of an area mixed with foreign substances after melting. In addition, when the weld joint hardening index is $17.7 \%$ or more, the group that needs to consider quality deterioration for weld joint 
hardening is classified. Thus, quality deterioration characteristics, according to the dilution ratio, were established.

(2) To determine the weld joint hardening phenomena of $9 \% \mathrm{Ni}$ steel caused by welding process variables, the quality deterioration characteristics were learned in the SVM technique and it was determined whether the group with quality deterioration could be accurately identified. As a result, it was confirmed that a group with the hardening of a weld joint was predicted $100 \%$ repeatedly. This result was used as a procedure to determine the deterioration of weld joint quality.

(3) A response surface method mathematical prediction model was developed to apply an objective function to optimize the welding process variables where quality deterioration occurs. By entering the raw data of weld joint hardening into the optimization algorithm created by the objective function and constraint conditions, the quality degradation characteristics contained in the process variables were supplemented.

(4) The predicted welding factors were calculated by entering the input variables supplemented for their quality degradation characteristics into the response surface mathematical model. By re-entering the corresponding output variables into the discrimination system, all the raw data where the hardening of a weld joint was expected, showed no quality deterioration.

Author Contributions: Conceptualization, M.P. and K.C.; methodology, M.P.; software, C.P. and K.C.; validation, K.C., J.K. (Jisun Kim).; formal analysis, M.P.; investigation, M.P.; resources, J.K. (Jaewoong Kim); data curation, M.P.; writing-original draft preparation, M.P.; writing-review and editing, M.P., J.K. (Jisun Kim), C.P., J.K. (Jaewoong Kim), K.C.; visualization, C.P.; supervision, J.K. (Jaewoong Kim), K.C.; project administration, J.K. (Jaewoong Kim), K.C.; funding acquisition, J.K. (Jaewoong Kim); All authors have read and agreed to the published version of the manuscript.

Funding: This study was conducted with the support of the Korea Institute of Industrial Technology as "The dynamic parameter control based smart welding system module development for the complete joint penetration weld (KITECH EH-21-0003)".

Institutional Review Board Statement: Not applicable.

Informed Consent Statement: Not applicable.

Data Availability Statement: The data presented in this study are available on request from the corresponding author.

Conflicts of Interest: The authors declare no conflict of interest.

\section{References}

1. IMO. Regulations to Reduce Air Pollution from Ships and the Review of Fuel Oil Availability; IMO: London, UK, 2016.

2. Kim, K.; Park, K.; Roh, G.; Ghun, K. Case Study on Boil-Off Gas (BOG) Minimization for LNG Bunkering Vessel Using Energy Storage System(ESS). J. Mar. Sci. Eng. 2019, 7, 130. [CrossRef]

3. Lee, Y.H. Analysis of the Characteristics of Reformer for the Application of Hydrogen Fuel Cell Systems to LNG Fueled Ships. J. Korean Soc. Mar. Environ. Saf. 2021, 27, 135-144. [CrossRef]

4. Peng, Y.; Zhao, X.; Zuo, T.; Wang, W.; Song, X. A systematic literature review on port LNG bunkering station. Transp. Res. Part D Transp. Environ. 2021, 91, 102704. [CrossRef]

5. Chang, W.S.; Kim, K.C.; Kim, Y.C.; Kim, S.R.; Kim, W.S. Ni alloy welding consumables for 9\% Nickel steel. Korean Weld. Join Soc. 1998, 16, 25-37.

6. ASTM E23. Standard Test Methods for Notched Bar Impact Testing of Metallic Materials. Standard Test Methods for Notched Bar Impact Testing of Metallic Materials. Am. Soc. Test. Mater. 2007, 7a, 1-6.

7. Park, M.; Kim, J.; Pyo, C.; Son, J.; Kim, J. A Study on the Algorithm of Quality Evaluation for Fiber Laser Welding Process of ASTM A553-1 (9\% Nickel Steel) Using Determination of Solidification Crack Susceptibility. Materials 2020, 13, 5617. [CrossRef] [PubMed]

8. Yun, T.; Oh, W.; Lee, B.; Lee, C.; Na, H.; Choi, J.; Kim, I. A Study on Optimization of Fillet in Laser Welding Process for 9\% Ni Steel Using Gradient-Based Optimization Algorithm. J. Weld. Join. 2020, 38, 485-492. [CrossRef]

9. Na, K.; Lee, C.; Park, J.; Cho, M. A Comparison of Hot Cracking in GTAW and FCAW by Applying Alloy 625 Filler Materials of 9\% Ni Steel. J. Weld. Join. 2019, 37, 357-362. [CrossRef] 
10. Kim, B.; Park, J.; Lee, J.; Kim, M. Study on the Initial Design of an LNG Fuel Tank using 9 wt.\% Nickel Steel for Ships and Performance Evaluation of the Welded Joint. J. Weld. Join. 2019, 37, 555-563. [CrossRef]

11. Watanabe, I.; Suzuki, M.; Matsuda, Y.; Tagawa, H.; Matsui, K.; Shimada, S. Fracture toughness of $9 \%$ Ni steel and safety of LNG storage tank against brittle fracture. Nippon Kokan Tech. Rep. 1984, 42, 2-10.

12. Liu, X.; Athanasiou, C.E.; Padture, N.P.; Sheldon, B.W.; Gao, H. A machine learning approach to fracture mechanics problems. J. Acta Mater. 2020, 190, 105-112. [CrossRef]

13. Oh, D.J.; Lee, J.M.; Noh, B.J.; Kim, W.S.; Ando, R.; Matsumoto, T.; Kim, M.H. Investigation of fatigue performance of low temperature alloys for liquefied natural gas storage tanks. J. Mech. Eng. 2015, 229, 1-15. [CrossRef]

14. Kourshid, A.F.M.; Ghanem, M. Using the welding parameters to improve the mechanical properties of Liquefied Natural Gas storage tank welded joint. IOSR J. Mech. Civ. Eng. 2012, 4, 32-39. [CrossRef]

15. Technical Report 9\% Nickel Steel: For Use at Cryogenic Temperatures; ArcelorMittal: East Chicago, IN, USA, 2010.

16. Kobelco's Welding Consumables for LNG Storage Tanks Made of 9\% Ni Steel. Kobelco Weld. 2011, 14, 3-8.

17. Paura, R. IPG Fiber lasers: What's new in applications for fabricators. In Proceedings of the ALAW Laser Application Workshop, Plymouth, MI, USA, 13-14 May 2009.

18. Kim, Z.H. A Comparative Study of Classification Techniques Using Forest Cover Type Data: Discriminant Analysis, Logistic Regression, Neural Network, Decision Tree. Unpublished Master's Thesis, Chung-Ang University, Seoul, Korea, 2012.

19. Amrine, D.E.; White, B.J.; Larson, R.L. Comparison of classification algorithms to predict outcomes of feedlot cattle identified and treated for bovine respiratory disease. Comput. Electron. Agric. 2014, 105, 9-19. [CrossRef]

20. Knowles, J.D.; Corne, D.W. Approximating the nondominated front using the pareto archived evolution strategy. Evol. Comput. 2000, 8, 149-172. [CrossRef] [PubMed]

21. Vapnik, V.N. The Nature of Statistical Learning Theory; Springer: Berlin/Heidelberg, Germany, 1999.

22. Deb, K.; Agrawal, S.; Pratap, A.; Meyarivan, T. A fast elitist non-dominated sorting genetic algorithm for multi-objective optimization: NSGA-II. Lect. Notes Comput. Sci. 2000, 1917, 849-858.

23. Zitzler, E.; Deb, K.; Thiele, L. Comparison of multiobjective evolutionary algorithms: Empirical results. Evol. Comput. 2000, 8, 173-195. [CrossRef] [PubMed]

24. Veldjuizen, D.A.V.; Lamont, G.B. On measuring multiobjective evolutionary algorithm performance. Evol. Comput. 2000, 1, 204-211.

25. Deb, K.; Pratap, A.; Agarwal, S.; Meyarivan, T.A. A fast and elitist multi objective genetic algorithm: NSGA-II. IEEE Trans. Evol. Comput. 2002, 6, 182-197. [CrossRef] 